\title{
Normative and Recognitional Concepts
}

\author{
ALLAN GIBBARD \\ University of Michigan, Ann Arbor
}

I can ask myself what to do, and I can ask myself what I ought to do. Are these the same question? We can imagine conjuring up a distinction, I'm sure. Suppose, though, I just told you this: "I have figured out what I ought to do, and I have figured out what to do." Would you understand immediately what distinction I was making? To do so, you would have to exercise ingenuity. I have in mind here an "all things considered" ought that I can use in my thinking, an ought that is not specifically moral, in that it doesn't settle by sheer rules of language that I ought always to abide by morality. For this ought, the question of what I ought to do seems just to be the question of what to do

Let's experiment, then, with accepting this suggestion. It commits us to something of theoretical import. The answer to an ought question is a statement; I can state this: I ought to speak loudly enough in public that people can hear. If I settle what to do, though, I voice my conclusion not with a statement, but with something like an imperative: "Speak audibly," I might tell myself. If the question of how loudly to speak is open, then my words express a decision-whereas if I say "I ought to speak audibly," my words seem to express a belief, a belief as to what I ought to do. Can a decision, then, also be a belief? And if so, what is the content of this belief?

To explore the hypothesis I have broached, I shall look not at how our words and concepts do work, but at how they might work if the hypothesis were correct. The claim I'll argue is this: Being in the business of acting and planning commits us to something ought-like. If the ought I have suggested we find in our thoughts did not exist, we'd be committed to its invention. It is in the nature of living, deciding, and planning that the thinking involved acts as if it were coping with facts-with facts of a special kind, facts of what one ought to do.

What kinds of facts are these? My answer will be a little complex, and it will be somewhat Moorean: it will fit a plausible reading and emendation of G. E. Moore's doctrines. At this point in my exposition, I'll have to be 
oracular: First, I say, given my circumstances, there is a property of being the thing to do in those circumstances. This property isn't in any way "queer", as Mackie might charge;' in a sense, it is an ordinary, natural property-though it may be a complex one, the resultant of a delicate balancing of considerations. On this score, I am somewhat like the "naturalistic moral realists" centered at Cornell University. ${ }^{2}$ They think that moral terms like 'just' and 'good' refer to natural properties. For purposes here, we might invent a Cornell-like character, the "naturalistic practical realist", who maintains that the phrase "the thing to do" likewise picks out a natural property. ${ }^{3}$ I am saying that, insofar as this particular doctrine goes, this naturalistic practical realist is right. Indeed for all my arguments show, this property might be something straightforward like pleasure, or more precisely, holding out maximal prospects for net pleasure. The metapractical arguments in this paper will leave it entirely open what this property is. This part of my doctrine is Moorean, in that G. E. Moore spoke somewhat obscurely about "the good" -which, he allowed, might be pleasure, say, for all his arguments strictly about meaning show. ${ }^{4}$ read Moore as getting at just what I'm saying here. For a given set of circumstances, there is a property of being the thing to do in those circumstances, and this property more or less fits Moore's notion of a natural property.

On the other hand-again with Moore, as I read him-I want to insist that the concept of being the thing to do is quite special. It is different from any descriptive concept of a natural property. To apply this concept to an act that is open to one is to settle on the act, to decide to do it. No naturalistic, descriptive concept has this feature. I have characterized this concept of "being the thing to do" so that a form of "internalism" applies to it automatically, the kind that Stephen Darwall calls "judgment internalism". As Mackie might put it, the concept has to-be-doneness built into it. ${ }^{6} \mathrm{I}^{\prime} l \mathrm{ll}$ be arguing, though, that while practical concepts are special in this regard, they needn't be "queer" or mysterious in any way. They work just as we should expect as we investigate decision and contingency planning.

My argument, then, will take the form of a possibility proof. I won't be claiming anything directly about our actual concepts. I will be claiming that planning involves commitment to a predicate, a predicate that acts much as

Mackie, Ethics (1977), pp. 28-42, offers an "argument from queerness" against objective ethical properties.

2 Boyd, "How to Be a Moral Realist" (1988); Sturgeon, "Moral Explanations" (1985). Sturgeon, in "Gibbard" (1985), p. 26, discusses definitions which "do not pretend to be analytic" and, "when correct, tell us the nature of what the term refers to."

3 Peter Railton suggested the phrase "the thing to do" to me as best capturing the concept I want to study.

$4 \quad$ Moore, Principia Ethica (1903), pp. 8-9.

5 Darwall, "Internalism and Agency" (1992), pp. 160-62.

6 Mackie, Ethics (1977), p. 40. 
Moore thought the predicate 'is good' acts. The planner is committed to thinking that this predicate signifies a natural property, a property of acts in their contexts. He is also committed to treating this predicate as special, as characterized by motivational judgment internalism - and so not equivalent to any naturalistic-descriptive predicate. The doctrine I'll claim to establish, then, amounts to naturalism for practical properties, and non-naturalism for practical concepts.

Simon Blackburn has long pursued a program he labels "quasi-realism". In the normative realm, this consists in starting from a non-descriptive account of normative concepts, and then showing that from this account it follows that they behave very much like descriptive concepts. ${ }^{7}$ My talk of a natural property that constitutes being the thing to do may sound too metaphysical to Blackburn, but I think of what I'll be saying as realizing his program. If I am right, then many of the contrasts that have been supposed to distinguish "realism" from "antirealism" in ethics fail in fact to do so. My treatment of normative concepts is distinctive not because I deny that they pick out natural properties-for in a sense, I don't deny this-but in my account of how they do so, of how normative concepts pick out natural properties: they do so, I say, by expressing aspects of a general policy for living.

The argument will proceed in a number of steps. I start with decision and planning, and expressions of the conclusions one arrives at in planning. "In poisonous snake country, step on a fallen log and not over it," I can tell myself, and I thereby express a conclusion I arrive at in my contingency planning. What, then, licenses me to express this as a statement? I state, "In snake country with a log across the path, the thing to do is to step on the $\log$, not over it." How I can do this is, in effect, the dread "Frege-Geach" problem that Geach and Searle developed for certain kinds of metaethical theories. ${ }^{8}$ I offered a solution to this problem in my book of several years ago, and I'll ask what it is about planning and the like that allows this solution to go through. My quasi-realistic contentions will then fall out of this solution to the Frege-Geach problem: that given a situation in which one must decide, there is a natural property that constitutes being the thing to do in that situation. If the language as I describe it doesn't already exist as our normative language, it is available to be invented-and it will be hard to see how we could have gotten along for so long without it.

A parenthetical note before I proceed: I'll be ignoring all questions of indifference, all questions of ties in the outcome of deliberation. I believe I could, with more discussion, allow that a planner might find more than one option admissible, and so think no act uniquely the thing to do. It will

Blackburn, Essays in Quasi-Realism (1993), p. 15.

Searle, "Meaning and Speech Acts" (1962); Geach, "Assertion" (1965).

Gibbard, Wise Choices (1990), 83-102. 
simplify matters, though, to leave all such tied outcomes to one side, and explore some other time whether Buridan's ass could find cause to balk at my treatment.

\section{Thinking What to Do}

Holmes is stalked by Moriarty, imagine. He plans to escape by train, packing as late as possible to conceal his intentions. By now, though, it may be too late to catch the train-in which case packing is useless. Thinking through the considerations, he decides to start packing. He says,

Packing is now the thing to do.

We explain easily what his words mean; they simply express his decision to pack.

Now the Frege-Geach problem raises its head. Holmes ascribed a predicate to packing; he predicated of it being now the thing to do. We haven't, though, explained this as ascribing a property to packing, some "queer" property laden with to-be-doneness; his words simply expressed his decision. But the predicate can appear in a wide variety of other contexts too, contexts in which no decision is being expressed. Holmes might have said this to himself:

Either packing is now the thing to do, or by now it's too late to catch the train anyway.

He could then include this disjunction in an argument. Join (2) with the premise

It's not even now too late to catch the train.

The conclusion seems to follow,

$\therefore$ Packing is now the thing to do.

How, then, do we explain what is meant by 'is the thing to do' in a disjunctive context like (2)? This predicate figures in Holmes's reasoning, and seems, in this deduction, to act much like any other predicate. What makes his reasoning valid, if it is-and why, here, does validity seem to act so much like validity in reasoning with plain descriptive predicates?

To accept the disjunction (2) all by itself isn't to make a decision; (2) doesn't tell Holmes straight out what to do. As we have seen, though, it can bear on what to do. Put disjunction (2) together with the descriptive premise (3), and Holmes can reason to a decision.

What does Holmes do in accepting a disjunction like (2)? What, indeed, do I do in accepting any disjunction? I rule out a possibility. A disjunction ( $A$ or 
$B$ ), as we all know, precludes the case where $A$ and $B$ are both false. The force of the precluding is this: If I accept $(A$ or $B)$, I can't then come both to reject $A$ and to reject $B$ - unless, that is, I change my mind, either knowingly or by losing track of my thinking.

What, then, of an argument, $(A$ or $B)$, not $A$, therefore $B$ ? With the first I rule out this: coming both to reject $A$ and to reject $B$. With the second I reject $A$. The combined effect, then, is to rule out rejecting $B$. It would therefore be inconsistent of me to accept the premises and reject the conclusion: I would be doing what I had ruled out doing.

This explanation applies whether or not the disjunctive reasoning is couched in terms that are purely descriptive. It applies to reasoning from a descriptive disjunction $(A$ or $B$ ), and it applies equally to Holmes's reasoning from the mixed descriptive-practical disjunction (2). If Holmes accepts the disjunction (2), he rules out the following: coming both (i) to reject its being too late to catch the train and (ii) to reject packing. With (3), he rejects its being too late to catch the train. He has thus ruled out rejecting packing.

It would be good to have a way to keep track of such inferential import. How might we code the inferential import of disjunctions and the like? Holmes's disjunction (2) rules something out: it rules out a combined state of describing and deciding, of judging how things are and judging what to do. Two issues are in play, one an issue of how things are, and one an issue of what to do:

a) whether it's too late to catch the train, and

b) whether to start packing.

This makes for four possible combinations of pertinent settled belief and decision-four combinations that Holmes might come to if he settles his mind on both of these matters:
$C_{L P}$ : Believing it's too late and deciding to pack
$C_{L P}$ : Believing it's too late and deciding not to pack
$C_{L P}$ : Believing it's not too late and deciding to pack
$C_{L P}$ : Believing it's not too late and deciding not to pack

Since these are the states of mind he can be in if he has decided both what to believe and what to do, I'll call them decided states. We can now represent the content of the disjunction (2) by which of these decided states it rules out and which it doesn't. What it rules out is $C_{L P}$, believing it's not too late and still deciding not to pack. The disjunction rules out none of the other three 
decided states: $C_{L P}, C_{L P}$ and $C_{L P}$. Say, then, that a judgment allows a decided state just in case it doesn't rule it out. (For a judgment to "allow" a decided state, then, is not for it to preclude ruling that state out; it is just for that judgment not by itself to rule out that decided state.) The content of the disjunction (2), then, we can represent by the set $\left\{C_{L P}, C_{L P}, C_{L P}\right\}$ of docided states it allows. It rules out all decided states but these-that is, it rules out the single decided state $C_{L P}$.

What is it about decision that makes such a solution work? We cannot just coin predicates to do any linguistic work whatsoever: Dreier imagines inventing a predicate 'is hiyo' to be used in accosting: If I say 'Bob is hiyo', that's just a declarative style of saying "Hey, Bob!" I can't, though, reason to an accosting, and a disjunction using this purported predicate would make no sense. ${ }^{10}$ Try saying this:

Bob is in a hurry or he is hiyo.

To ascribe 'is hiyo' to a person, we have explained, is to hail him, but this explanation fails to give any meaning to a disjunction like (4). We cannot transform hailings, then, into ascriptions of predicates. Why think we can so transform expressions of decisions?

Two observation may serve to answer Dreier's challenge. First, the scheme I have sketched applies only to expressions of states of mind. Prosaically factual statements are expressions of prosaically factual beliefs, and "thing to do" statements, as I am treating them, are expressions of decisions, actual or hypothetical. Second, though, and crucially, the states of mind expressed can be agreed with or disagreed with. A groan, say, might express a headache, but there's no agreeing or disagreeing with a headache. A decision, in contrast, is something one can agree with or disagree with. One can stick with it over time, or change one's mind, and different people, at different times, can agree with it or disagree with it. Disagreement holds the key: the possibility of agreeing or disagreeing with a state of mind makes that state of mind act logically like accepting a claim. ${ }^{11}$ Charles Stevenson was quite right to begin his presentation of emotivism with disagreement: he begins with "disagreement in attitude", a kind of disagreement that can mimic, in important ways, disagreement in belief. ${ }^{12}$ One can't agree or disagree with a hailing - though one can agree or disagree with a decision to hail, or with a belief, say, that Bob has been hailed. Likewise with headaches. But I can agree or disagree with Holmes' decision to pack-and Holmes might later himself come to disagree with it.

10 Dreier, "Expressivist Embeddings" (1996), pp. 42-44.

11 Brandom, Making It Explicit (1994), 592-97 and elsewhere, discusses the making of a single claim from multiple perspectives.

12 Stevenson, Ethics and Language (1944), 2-8. 
This is what allows the simple apparatus I have constructed. Let me now expand the apparatus. Holmes makes not only decisions for what to do on the spot, but contingency plans: he can decide to flee the station if the train is more than two minutes late. I myself can decide hypothetically for the same situation: I can decide what to do for the case of being Holmes in that situation. I decide, suppose, "If in that situation, stay at the station, but pay a cab to speed off as a decoy." In that case, I disagree with Holmes's own decision for that circumstance.

Back, then, to decided states. We can now imagine, as an idealization, my reaching a state of mind that is decided on everything. In such a hyperdecided state, I would have a complete view, correct or incorrect, about everything that might be the case in the world, and I would have a universal plan for life, a plan that covers, in detail, every possible situation one could be in that calls for a decision. We can now represent the force of, say, disjunction by specifying in which such hyperdecided states I would not have changed my mind about the disjunction. I would accept the disjunction if and only if I accepted one of its disjuncts.

All of truth-functional logic can be put in these terms. Inconsistency in one's descriptive-practical state of mind consists in this: there being no possible hyperdecided state one could reach without rejecting something one now accepts. And we have this important principle: One is committed to everything one couldn't consistently reject without changing one's mind about something. Therefore, suppose I would accept a claim $C$ in every possible hyperdecided state I could reach without changing my mind about something-without rejecting something I now accept. Then I am already committed to claim $C$. This is a principle I will cite in my crucial argument of the next section of the paper: Take any claim $C$. Suppose that for every hyperdecided state I could reach without changing my mind, I would accept $C$ if in that state. Then, the principle says, I am already committed to $C$.

As an illustration, the principle underwrites this logical truism: Suppose $P \& Q$ entails $S$ and $P \& \neg Q$ entails $S$; then $P$ entails $S$ by itself. A friend Jane, suppose, accepts $P$, that you speak Polish. She might then refine her views by coming to accept $Q$ as well, that you speak Quechua, or might refine her views by coming to accept $\neg Q$. Indeed any way whatsoever of becoming coherently hyperdecided without changing her mind about anything consists, among other things, either in accepting $P \& Q$ or in accepting $P \& \neg Q . P \& Q$ entails $S$, that you can speak, in that any coherent way of accepting $P \& Q$ and being decided on $S$ consists, among other thing, in accepting $S$. Likewise for $P \& \neg Q$. Hence since both entail $S$, any coherent way she has of being decided on $S$ without changing her mind on $P$ involves accepting $S$. Thus $P$ entails $S$; the principle has done its work. 


\section{Natural Constitution}

When I announced at the outset what I would be claiming, I distinguished concepts and properties. The property of being the thing to do, I said, is a natural property, but the concept of being the thing to do isn't a descriptive concept of that property. The kind of contrast I have in mind figures in this stock example: Consider a pre-scientific concept of being water, and the chemical concept of being $\mathrm{H}_{2} \mathrm{O}$, having molecules with two hydrogen atoms and an oxygen atom. These are different concepts; it comes as a discovery that water is $\mathrm{H}_{2} \mathrm{O}$. Mastery of the concepts alone isn't sufficient to yield this discovery. Still, just one property is in play: the property of being $\mathrm{H}_{2} \mathrm{O}$. The term 'water', we could say, signifies this property, and so does the term ' $\mathrm{H}_{2} \mathrm{O}$ '. The property of being $\mathrm{H}_{2} \mathrm{O}$ is what constitutes being water: in any possible situation, all and only water is $\mathrm{H}_{2} \mathrm{O}$.

A similar pattern holds for being the thing to do and some natural property. Logical apparatus won't settle by itself what this property is. Rather, to say what natural property this is would be to offer an answer, in complete and fundamental terms, to the general question of how to live. I won't be offering any such general answer; I only wish I could. Let me illustrate the possibilities, however, by exploring what is perhaps the most prominent answer to the question of how to live, egoistic hedonism. One accepts this answer if one decides, as one's plan for how to live, always to do whatever maximizes one's hedonic prospects, one's prospects for a balance of pleasure over displeasure in one's life. Much debate among philosophers has concemed what pleasure is and how most effectively to pursue it, but for my illustrative purposes, let's suppose that these questions are answered.

Hedda, imagine, is a hedonistic egoist: her contingency plan is always, in any possible situation, to do what maximizes her hedonic prospects. She thinks, then, that in any possible situation, the thing to do is the thing that maximizes one's hedonic prospects. This amounts to saying, as I'll put it, that maximizing one's hedonic prospects is what constitutes being the thing to do. "Constitution" here works on a parallel to a way we might understand water and $\mathrm{H}_{2} \mathrm{O}$ : just as any possible situation, something is water iff it is $\mathrm{H}_{2} \mathrm{O}$, so in any possible situation, according to Hedda, something is the thing to do just in case it maximizes the agent's hedonic prospects.

Is this really a matter of constituting? Does Hedda, in making a contingency plan, really commit herself to anything so metaphysical sounding as this? There are a multitude of ways of thinking about properties, concepts, and constitution, and I couldn't hope to prove that my terminology fits all these ways. Here, though, is how I propose to think about the matter. Constitution, we can say, involves being coextensive necessarily. To say that two concepts are necessarily coextensive is just to say that for every possible situation to which the concepts apply, all and only things that fall under the 
one fall under the other. Being $\mathrm{H}_{2} \mathrm{O}$ constitutes being water, after all, in that in any possible situation, all and only $\mathrm{H}_{2} \mathrm{O}$ would be water. ${ }^{13}$ Now according to Hedda, all and only acts that maximize the agent's hedonic prospects are the thing to do. In other words, in her opinion, the concept of being the thing to do is coextensive with that of maximizing one's hedonic prospects. Indeed this holds, she maintains, for any possible circumstance a person might occupy-for her contingency plan for being in any possible circumstance whatsoever is to maximize her hedonic prospects. She thus takes maximizing one's hedonic prospects to be the thing to do in any possible situation. In other words, in her opinion, the concept of being the thing to do is necessarily coextensive with that of maximizing one's hedonic prospects. If necessary coextension amounts to constitution, this amounts to saying that maximizing one's hedonic prospects constitutes being the thing to do. The metaphysical jargon I'm employing is just a fancy way of putting something ordinary - even vulgar, some would say - that Hedda maintains.

Perhaps, though, constitution involves a kind of explanatory dependency as well. ${ }^{14}$ Being water depends on being $\mathrm{H}_{2} \mathrm{O}$, is explained by being $\mathrm{H}_{2} \mathrm{O}$, in a way that doesn't reverse; that, perhaps, is why what constitutes being water is being $\mathrm{H}_{2} \mathrm{O}$ but not the other way around. Water is what it is because it is $\mathrm{H}_{2} \mathrm{O}$, but we don't say that $\mathrm{H}_{2} \mathrm{O}$ is what it is because it is water. Now I don't know how we might best formulate this asymmetry, but informally, it seems to work too with Hedda's views on being the thing to do: If an act is the thing to do, she'll maintain, that's because it maximizes the agent's hedonic prospects. She won't claim that it maximizes one's hedonic prospects because it's the thing to do.

Hedda thinks that with being the thing to do and maximizing one's hedonic prospects, a single, natural property is in play. Still, she must insist, these are two distinct concepts: the practical concept of being the thing to do, and the descriptive concept of maximizing one's hedonic prospects. The test for concepts is what agreement or disagreement consists in. Percy, imagine, is a perfectionist: his universal plan, for any possible situation one might face, is to do what in prospect most promotes his perfection. He has, let's imagine, some explicit, descriptive characterization of what makes for perfection; call this percifection. Take, then, any choice situation in which, as Hedda and Percy agree, going to bed maximizes one's hedonic prospects, but staying up and doing piano exercises maximize one's prospects for percifection. They disagree on which of these is the thing to do in that situation, though they agree on which maximizes one's hedonic prospects.

13 See Kripke, "Naming and Necessity" (1972), pp. 126-29, on water as a natural kind, in counterfactual circumstances.

14 Kim, Supervenience and Mind (1993), pp. 149-56, defines a concept of "strong covariance" and then characterizes supervenience as this plus a kind of asymmetric dependence. He argues that this entails at least infinite reducibility. 
Let me pause here to stress one lesson of this example: in questions of what's the thing to do, thinking needn't make it so. Hedda may think that in her situation, the thing to do is to head for bed—and this may fit perfectly her comprehensive, hedonistic view of how to live. But Percy disagrees on what's the thing to do in her situation, and whether or not he is right, his view is coherent. So if Hedda and Percy are each coherent and they disagree, which of them is right? To come to a view on that, you and I must ourselves think how to live. In particular, we must settle what to do if in Hedda's exact situation. Hedda's own, coherent decision needn't settle the matter: we can judge that she is wrong. And if we do, then whether we are right or she is won't be settled by the metapractical claims I have been making. The question will be how to live-what, ultimately, to seek in one's actions and plans.

\section{The Argument for Natural Constitution}

Hedda, as I have stipulated her plans, thinks in effect that she knows what constitutes being the thing to do: the property of holding out maximal hedonic prospects. This Moore would count as a natural property, and so in this sense, she thinks that there is a natural property that constitutes being the thing to do. Most of us, though, aren't in her condition: we're not pure egoistic hedonists-and we aren't pure perfectionists either. Most of us don't have a fully worked out basic view on how to live; we muddle though. Yet I am claiming that as deciders and planners, we are each committed to this claim of constitution: that there is a property that constitutes being the thing to do, and it is, in some sense, a natural property. Why do I say this?

The key lies in the workings of hyperdecided states. In a hyperdecided state, remember, one has settled on a universal plan, a plan for what to do in any possible circumstance. Now a planner must identify acts in terms of their natural properties: a plan, say, always to do whatever is the thing to do is no plan at all. A universal plan can take the infinite form, in situation $S_{1}$ do the act with natural property $P_{1}$, in situation $S_{2}$ do the act with natural property $P_{2}$, and so on. From this, we can construct the grand property, having $P_{1}$ in $S_{1}, P_{2}$ in $S_{2}$, etc. Call this property $P^{*}$; the plan is, then, in any possible situation, to do the act with this grand property $P^{*}$. In a hyperdecided state, this shows, one accepts that there is a property that constitutes being the thing to do-namely $P^{*}$. And this property is constructed, finitely or infinitely, out of natural properties.

What, then, of the rest of us: ordinary, doubt-ridden humanity, who are far from hyperdecided. To elicit the logic of our concepts, l'll work with a vast idealization, that my ordinary Joe, uncertain though he is, is nevertheless consistent. We return now to the Principle of Commitment that I defended at the end of the Section before last. Consider the many ways that Joe could become hyperdecided without changing his mind on anything. Take a conclu- 
sion $Q$ that he would accept no matter what decided state he might come to be in without changing his mind. This, then, is something to which Joe is committed; it is entailed by what he already accepts. The principle, then, reads as follows:

PRINCIPLE OF COMMITMENT. A person is committed to a claim $Q$ if in every coherent hyperdecided state he could reach without changing his mind, he would accept $Q$.

Now in any hyperdecided state whatsoever, we have been saying, Joe would accept the Claim of Constitution. A fortiori, he accepts the Claim of Constitution in any hyperdecided state he could reach without changing his mind about anything. The Principle of Commitment thus applies to him, and so he is committed to the Claim of Constitution, whatever his other uncertainties. And so are you, so am I, and so is any planner.

Having established what we are all committed to, I can now assert it: There is a property-natural in a sense-that constitutes being the thing to do. So say I, and so must you agree; this is the transcendental turn in the argument.

In metaethical discussions, people often talk as if certain properties were peculiarly moral. The question then seems to press theorists, whether these are some subclass of natural properties, or some special kind of non-natural property-or whether there are no such properties at all. Morality has not directly been my topic; I have rather been seeing what happens if we start in a realm in which expressivism has to be right, with expressions of decisions. My conclusions about practical thought have then turned out to mirror much of what G.E. Moore says in a metaethical vein. The property that constitutes being the thing to do might indeed be complex, the resultant of a balancing of diverse considerations. Even if it is, however, that leaves another contrast that is crucial to understanding practical thought. The pattern I have described, after all, applies even if the property that constitutes being the thing to do is a natural property of a plain and straightforward kind. It applies if, say, an egoistic hedonist like Hedda is right, and this property is that of maximizing one's hedonic prospects. Moore's non-naturalism might best be freely read as a doctrine not about properties but about concepts. Call the property that constitutes being the thing to do $P^{*}$, and let $D$ be a descriptive concept of this property. Moore's point, so emended, is this: people who disagree about what's the thing to do don't necessarily disagree on which acts are $D$. Their disagreement may not be descriptive, but purely a matter of what to do and how to live. In philosophers' jargon, it may be practical.

Here, then, is a slogan: All properties are natural, but not all concepts of properties are descriptive. Some instead are practical. 


\section{What Sort of Property}

What kind of property does the proof I have given establish? What kind of property must this be, the property that constitutes being the thing to do?

For sure, it can't be a natural property in the sense that we conceive it, as we plan, in terms of fundamental physics. We cannot guide our lives by anything so esoteric: "Keep away from radioactivity" would surely be a good part of a plan for living, if only we knew how to tell what's radioactive-but not much help if we don't. Plans, it seems, must be couched in terms of features that we can recognize: features of contingencies and features of options. Both these must be available to the person who follows the plan. "Buy low, sell high" is no plan we can implement. The building blocks of a contingency plan must be concepts that are recognitional, concepts in terms of which we can recognize the circumstance we're in, and in terms of which we can settle what to do and so do it.

What, then, of the property that constitutes being the thing to do? It is constructed, I have said, from the properties of contingencies and options. A hyperplan could go, "In contingency $C_{1}$ do act $A_{1}$, in contingency $C_{2}$ do act $A_{2}$, and so on." It thus amounts to a plan to do all and only acts with this property: being act $A_{1}$ in contingency $C_{1}$, or act $A_{2}$ in contingency $C_{2}$, and so on.

This talk of properties, though, is misleading. A plan is couched in concepts, not in properties separate from how they are conceived. I don't follow a plan just by glomming on to a property, but by conceiving it in terms of certain concepts. It's concepts, not properties, that are recognitional or not. The property of being wet may be identical to the property of having $\mathrm{H}_{2} \mathrm{O}$ adhering, but these concepts are not the same. If I don't know chemistry, I'll still recognize things as wet, but not through any such chemical concept. I should be talking, then, not in the first instance about the property that constitutes being the thing to do, but about a concept of it.

Speak, then, of the concept that realizes being the thing to do. This concept, I have been arguing, must be composable, though perhaps only infinitely, from recognitional concepts. Let's term this a recognitionally grounded concept. The relation I've been treating as constitution, then, begins with this relation among concepts, the relation of a concept's realizing being the thing to do. We start with a practical concept, the concept of being the thing to do, and now see that some recognitionally grounded concept realizes it. By that I mean, at least in part, that necessarily, all and only acts that fit this concept are things to do.

This concept is the concept of a property, but the same property may also be realized by other concepts-esoteric scientific concepts, for instance. Only recognitional concepts figure in plans fully specified. There is a property that constitutes being the thing to do, and a recognitionally grounded concept real- 
izes this property. The concept is naturalistic in this sense, and we could call the property natural, in the sense that it is picked out by such a naturalistic concept. In our new lingo, then, we can speak of the recognitionally grounded concept that realizes being the thing to do. (Hedda thinks that this is the concept of offering top hedonic prospects.) The pure planning concept being the thing to do likewise realizes this same property, but it is a distinct concept.

A concept that realizes being the thing to do is, I have argued, constructable out of recognitional concepts. The construction, though, might be infinite, for all the logic of planning by itself establishes; only in this loose way has the concept been proved naturalistic. I myself would find it bizarre if what to do were infinitely arbitrary, without discernible rationale. To think that it is would be to settle on leading one's life without discernible rationale. That is not, I am sure, the way to live-but nothing in the proof I have given speaks to this further claim. The question is an aspect of how to live: whether being the thing to do has an intelligible rationale. Answering this is beyond the powers of sheer logic, the logic how to live.

\section{Thick Recognition}

Understandings of one's situation, we might fear or might hope, can't always be factored into separate components of how things are, on the one hand, and what to do on the other. I may just "see" that Jason is sensitive, and seeing this can't be separated from finding reason to spare his feelings. Jason's being "shy and sensitive" is already practically laden for me: in finding him sensitive, I am already motivated to tread carefully on his feelings. ${ }^{15}$ (Or perhaps if I'm a bully, I am already motivated to bait him.)

Now this, if it is right, might seem to impugn the picture I have been sketching. If I recognize my situation by its demands, won't I, in my planning, have to include these demands in my specification of the circumstances for which I plan a given response? If so, it may seem, then I cannot have my sharp distinction between what to do and how things are, the distinction I have helped myself to throughout my argument. What to do is built into circumstances for which I must plan.

Let me accept that apprehensions of one's situation can be heavy with demands for action. I may just perceive maggots on a slab of meat as disgusting, and to do this is to shy away from the scene. Feelings may come before recognition of an object, so that, say, disgust comes before recognizing the maggots as such. You do not, then, apprehend the scene in terms free of all valence for what to do, and then proceed to make your decisions. The same will no doubt go for more complex apprehensions of social situations: appre- 
hending how things are often won't be separate from having a strong sense of what to do. ${ }^{16}$

All this I am eager to accommodate-in the right way. Distinguish two ways in which we might try to accept these points. Only one of them is tenable, I'll argue; the other would yield monstrous directives for how to live. On the one hand, I'll agree, among an agent's circumstances is the fact that she has the sense she has of what her situation demands. Realizing that Jason is sensitive might involve having a sense that the way Jason is tells against joshing him. That Kathy has this sense may indeed be part of her situation. It is, though, a psychological aspect, not plan-laden in itself. Describing Kathy as having this sense does not at all commit us, logically, to being protective if in her shoes. A bully might plan for the case of being like Kathy and so having this sense that Jason is not to be joshed, and dismiss her concerns as wimpish, planning to weigh Jason's hurt feelings entirely in favor of joshing him. The bully is depraved but not thereby short on logic.

A stronger claim on this score must, though, be rejected. The untenable claim is that we must accommodate more than this, that when Kathy finds her circumstances to carry protective demands, we must recognize, as among her circumstances, that the situation indeed does carry these demands. If we were to accept this, then I agree, we would not be describing her situation in the kinds of terms I have in mind in speaking of plans for living. The terms we use will not bracket all questions of what to do.

The principle we'd need to accept in order to do this, though, is appalling. More to the point, the principle constitutes no demand of practical reason; it is one that a planner can reject without confusion. Our contingency planning, after all--even that of the most virtuous person imaginable-can include hypothetical decisions for the case of being vicious. Indeed part of genuine human virtue surely consists in just this: potentials for responding viciously are in us all, and we need to be prepared. Now, the vicious as well as the virtuous can experience a situation as demanding action. Turned vicious, I might find that a man's sexual persona demands bashing him up. I might be incapable of untangling my factual basis for this judgment from the glory, as I see it, of bashing up such a pathetic excuse for a man. A hyperplan covers all possible circumstances a person might be in, and so it covers this situation among others.

How, then, should I plan for such a plight? By discriminating, we might try answering, between virtuous and vicious sensings of what one's situation demands. What is it, though, when I view a hypothetical situation, to regard the demand-sensings I'd have in it as virtuous? Isn't it just to fall in, in my contingency plans for the situation, with the demands that I'd be sensing? Isn't it to give some weight, hypothetically, to meeting those seeming

16 Zajonc, "Feeling and Thinking" (1980). 
demands in that situation? What kinds of being "wimpish", as some would describe it, are vicious and what kinds virtuous? The answer doesn't come in advance of thinking how to live and what matters in living with others. Join me in thinking, then, what to do in the bashing case. In the situation we're planning for, one senses a seeming demand to bash, and we-the real we who are deciding hypothetically for that circumstance-can resolve to resist. We can each say to ourselves, "If something about a man I can't put my finger on seems to demand bashing him up, don't bash him, and work to get rid of my proclivity to sense such a demand."

As theorists of contingency planning, then, we need a framework that allows raising the question of whether a seeming demand is a veridical, whether it is a demand to fall in with. We must distinguish, in contingency planning, whether a sense I might have of what my plight demands is virtuous or vicious. And this brings us back to the first way of accommodating psychological point that situations may be recognized by their seeming demands.

Indeed we could lead ourselves back to that way just by thinking about contingency planning itself. It is no part of contingency planning to decide, hypothetically,

If something about a man really demands bashing, then bash him!

Or at least this is no part of contingency planning on the plainest interpretation of dictum (5). On this interpretation, the imperative (5) is analytic, but it applies to no possible circumstance. It is analytic in that it specifies the circumstance as one in which the man is, for no clear reason, to be bashed. It is inapplicable, though-and this is a substantive, practical claim-in that there are no such circumstances. To make the principle a genuine candidate for inclusion in a contingency plan, we would have to interpret the antecedent psychologically:

If something about a man seems to call for bashing, then bash him! (6)

But then the hypothetical decision is one a planner can reject-and that I hope we all do reject.

\section{Normativity}

I haven't been claiming overtly that my topic was normativity. My subject has been contingency planning, and the states of mind that could figure in it. These states of mind are possible, I have argued, if it is possible to agree or disagree in plans for living. If this is possible, then we are all committed to marks of realism in questions of how to live. The conclusions I drew sounded metaphysical: there is a property that constitutes being the thing to do in a 
situation, and there is a concept of that property that realizes being the thing to do. The concept is recognitionally based, and does not have demands for action built in. In this sense, the concept is descriptive and naturalistic, and the property is a natural property. Plan-laden concepts do signify natural properties, and in this regard, a naturalistic "practical realist" of a Cornell stripe would be right. A Moore-like non-naturalist would also, in a sense, be right: plan-laden concepts are not descriptive or naturalistic. Now perhaps, I'll voice a suspicion, we are familiar already with such plan-laden concepts, and our term of art for them is 'normative'. Whether this is so needs further inquiry.

\section{References}

Blackburn, Simon (1993). Essays in Quasi-Realism (New York: Oxford University Press).

Boyd, Richard N. (1988). "How to Be a Moral Realist". Geoffrey SayreMcCord (ed.), Essays on Moral Realism (Ithaca: Cornell University Press).

Brandom, Robert (1994). Making It Explicit (Cambridge, MA: Harvard University Press).

Darwall, Stephen (1992). "Internalism and Agency". Philosophical Perspectives 6, 155-74.

Dreier, James (1996). "Expressivist Embeddings and Minimalist Truth". Philosophical Studies 83, 29-51.

Geach, Peter (1965). “Assertion". Philosophical Review 74, 449-65.

Gibbard, Allan (1990). Wise Choices, Apt Feelings: A Theory of Normative Judgment (Cambridge, Mass.: Harvard University Press).

Kim, Jaegwon (1993). Supervenience and Mind: Selected Philosophical Essays (Cambridge, England: Cambridge University Press).

Kripke, Saul (1972). "Naming and Necessity". Donald Davidson and Gilbert Harman (eds.), Semantics of Natural Language (Dordrecht-Holland: Reidel).

Mackie, John L. (1977). Ethics: Inventing Right and Wrong (Harmondsworth, England: Penguin Books).

McDowell, John (1978), “Are Moral Judgments Hypothetical Imperatives?' Proceedings of the Aristotelian Society, supp. vol. 52, 13-29

Moore, G.E. (1903), Principia Ethica (Cambridge, England: Cambridge University Press).

Searle, John (1962), "Meaning and Speech Acts". Philosophical Review 71, 423-32.

Stevenson, Charles L. (1944). Ethics and Language (New Haven: Yale University Press). 
Sturgeon, Nicholas L. (1985). "Gibbard on Moral Judgment and Norms". Ethics 96, 22-33.

Sturgeon, Nicholas L. (1985). "Moral Explanations". David Copp and David Zimmerman (eds.), Morality, Reason and Truth (Totowa, New Jersey: Rowman \& Allanheld), 49-78.

Zajonc, R.B. (1980). "Feeling and Thinking: Preferences Need No Inferences". American Psychologist 35, 151-75. 